\title{
Influence of Copper Deficit on Structural and Metabolic Features of Myocardium of Rats in Conditions of Thyroid Hypofunction
}

\author{
Tetyana Guranych, Nataliya Voronych-Semchenko and Mykola Bagriy \\ Ivano-Frankivsk National Medical University, Ivano-Frankivsk 76000, Ukraine
}

\begin{abstract}
The research was carried on 60 rats, which were divided into two experimental groups - animals with thyroid hypofunction against iodine deficiency and on the background of combined iodine and copper deficit. The control group included 30 intact rats. For evaluation of copper balance its content was determined in erythrocyte mass and myocardium. Prooxidant-antioxidant system was examined by the level of peroxide oxidation of proteins and lipids and due to the activity of antioxidant enzymes. Structural features of the myocardium were examined by light-optical microscopy with subsequent morphometry. In the result of the experiment in rats with thyroid hypofunction on the background of combined iodine and copper deficit the redistribution of copper content in the studied tissues was established (accumulation in blood). The results of the study confirm the activation of oxygen-dependent processes in the myocardium of experimental animals, primarily due to peroxide oxidation of proteins, which is especially manifested in the context of combined iodine and copper deficiency. Metabolic changes in the myocardium were confirmed by histology. So, the development of thyroid hypofunction on the background of combined iodine and copper deficiency increases the probability of cardiovascular pathology due to disorders of prooxidant-antioxidant balance and structural changes in the myocardium.
\end{abstract}

Key words: Thyroid hypofunction, copper deficit, prooxidant-antioxidant balance, structure of myocardium.

\section{Introduction}

Essential trace elements, in particular copper, play an important role in ensuring the structural and functional properties of the heart. Copper is involved in the angiogenesis, the formation of elastin of the coronary arteries, regulates metabolic processes, mainly the intensity of lipoperoxidation [1]. Trace elements have two valence states and are cofactors of a variety of enzymes, providing a wide range of copper Redox potentials that regulate Redox activity in many cells, including cardiomyocytes [2]. Hypocupremia increases the risk of hypertension and myocardial hypertrophy. At the same time, thyroid hormones deficiency causes mucinous swelling of myocytes and interstitium, which eventually leads to the development

Corresponding author: Guranych Tetyana, $\mathrm{PhD}$, associate professor, research field: physiology. Email: guranichtanja@ukr.net. of fibrosis. Such changes are one of the predictors of the formation of atrioventricular blockages and variations of heart rhythm due to impaired excitability, automatism and conductivity of cardiomyocytes [3]. One important aspect is that copper deficiency leads to dyslipidemia and activation of atherogenesis processes, the intensity of which increases under conditions of thyroid dysfunction [4]. It should be noted that copper increases the activity of a number of hormones, in particular thyroxine, which in turn may affect the functional properties of the thyroid gland and cause changes in metabolic processes in the myocardium. That is why the purpose of the study was to examine the features of oxygen-dependent processes and structural changes in the rat's myocardium under the conditions of iodine and copper deficiency.

\section{Materials and Methods}

The research was carried on 60 male rats weighing 

Myocardium of Rats in Conditions of Thyroid Hypofunction

120-180 g, which were divided into two research groups $(n=30)$-animals with thyroid hypofunction against iodine deficiency $\left(\mathrm{TH}_{\mathrm{I}}\right)$ and rats with $\mathrm{TH}$ on the background of combined iodine and copper deficit $\left(\mathrm{TH}_{\mathrm{I}+\mathrm{Cu}}\right)$. Iodine deficiency was reproduced by keeping animals on an iodine-deficient diet [5]. TH was simulated by adding thyrostatic drug merkazolil ( 7.5 $\mathrm{mg} / 100 \mathrm{~g}$ body weight) to the drinking water of rats during 14 days [6]. After that, animals of the 1st experimental group continued to be maintained on an iodine-deficient diet, and for rats of the 2nd experimental group the copper deficiency was additionally modelled. Copper deficiency was reproduced by the daily addition of complexone d-penicillamine (cuprenil, "Polfa" Kutno Pharmaceutical Company, Poland) to drinking water of animals at a dose of $100 \mathrm{mg} / 100 \mathrm{~g}$ body weight for 21 days [7]. The control group included 30 intact rats, which were kept under the standard diet, normal temperature and light vivarium regimen. Euthanasia of animals was performed on the 36 day of the experiment by decapitation under ketamine anesthesia $(100 \mathrm{mg} / \mathrm{kg}$ of body weight).

To evaluate copper balance in animals, the trace element content was determined in erythrocyte mass and myocardium by atomic absorption spectrophotometry [8]. The processes of peroxidation in blood serum and myocardial homogenate were evaluated by the level of oxidative modifications of proteins (OMP), diene conjugates (DC) of polyunsaturated fatty acids, and active products that respond to thiobarbituric acid (TBA-AP) [9]. The antioxidant defense system was characterized by the activity of catalase (K), superoxide dismutase (SOD), glutathione peroxidase (GP), glutathione reductase (GR), ceruloplasmin (CP), saturation of transferrin with iron (STr) in blood serum [10].

The structural features of the myocardium were studied by light-optical microscopy. Photo documentation was performed using an Axioskop microscope and a Tucsen TCA-10.0-N digital camera using IS-capture (V. 1.0). Morpho- and densitometric studies were performed using UTHSCSA Image Tool Version 2.0 software for Microsoft Windows. Myocardial structure was evaluated by area and perimeter of cardiomyocyte nucleus, cardiomyocyte fraction, interstitial fraction, parenchymal-interstitial index.

All experiments were carried out according to the National Institute of Health Guidelines for the care and use of laboratory animals and the European Council directive on 24 November 1986 for Care and Use of Laboratory Animals (86/609/EEC), and approved by the Local Ethics Committee. Quantitative research results were analyzed using mathematical software package Statistic Soft 7.0 using the Student's $t$-test. Statistically significant difference was considered at $p$ $<0.05$.

\section{Results and Analysis}

In rats with $\mathrm{TH}_{\mathrm{I}+\mathrm{Cu}}$ the redistribution of copper content in the studied tissues was established (Table 1). Thus, the content of the trace element in the erythrocyte mass increased by 3.6 times $(p<0.05)$ against the background of its decrease in myocardial homogenate by $28.9 \%(p<0.05)$ compared to the control parameters.

The development of TH led to the activation of peroxidation processes in the examined tissues, mainly due to the intensification of peroxide oxidation of lipids (POL) (Table 2). In particular, the analysis of POL indices in animals with $\mathrm{TH}_{\mathrm{I}}$ detected a reliable manifestation of this process in blood serum, primarily due to the accumulation of final lipoperoxidation products. Thus, in the blood serum of rats of the 1st experimental group, the content of TBA-AP increased 2.2 times $(p<0.05)$ in comparison with indexes of intact animals. At the same time, the content of DC under the same experimental conditions decreased by $53.7 \%(p<0.001)$ relative to control.

In rats with $\mathrm{TH}_{\mathrm{I}+\mathrm{Cu}}$, the processes of POL were more pronounced. Thus, in the blood serum of animals of the 
Table 1 Copper content in erythrocytes and myocardium of intact rats, animals with thyroid hypofunction on the background of iodine deficiency, combined iodine and copper deficiency $(\mathbf{M} \pm \mathbf{m})$.

\begin{tabular}{lll}
\hline Group of animals & Erythrocytes & Myocardium \\
\hline Control group $(n=30)$ & $0.80 \pm 0.32$ & $3.43 \pm 0.42$ \\
1st research group $\left(\mathrm{TH}_{\mathrm{I}}, n=30\right)$ & $1.53 \pm 0.58$ & $3.70 \pm 0.26$ \\
2nd research group $\left(\mathrm{TH}_{\mathrm{I}+\mathrm{Cu}}, n=30\right)$ & $2.84 \pm 0.63^{*}$ & $2.44 \pm 0.10^{*}$ \\
\hline
\end{tabular}

$*_{-} p<0.05$ to analogical indexes in intact animals; $p$ with Arabic numerals - reliable difference between the indexes of correspondent research groups (here and in the next tables).

Table 2 The content of diene conjugates and products responding to thiobarbituric acid in the blood serum and myocardium homogenate of intact rats, animals with thyroid hypofunction on the background of iodine deficiency, combined iodine and copper deficiency $(\mathbf{M} \pm \mathbf{m})$.

\begin{tabular}{llc}
\hline \multirow{2}{*}{ Group of animals } & \multicolumn{2}{c}{ Diene conjugates, cu $\cdot \mathrm{mL}$} \\
\cline { 2 - 3 } & Blood serum & Myocardium \\
\hline Control group $(n=30)$ & $0.41 \pm 0.05$ & $1.35 \pm 0.17$ \\
1st research group $\left(\mathrm{TH}_{\mathrm{I}}, n=30\right)$ & $0.19 \pm 0.03^{\# \#}$ & $1.70 \pm 0.06$ \\
2nd research group $\left(\mathrm{TH}_{\mathrm{I}+\mathrm{Cu}}, n=30\right)$ & $0.23 \pm 0.06^{*}$ & $2.00 \pm 0.13^{* *}$ \\
\hline & Products responding to thiobarbituric acid, $\mathrm{nmol} \cdot \mathrm{mL}$ \\
\hline Control group $(n=30)$ & $3.13 \pm 0.81$ & $3.70 \pm 0.26$ \\
1st research group $\left(\mathrm{TH}_{\mathrm{I}}, n=30\right)$ & $7.00 \pm 1.36^{*}$ & $3.79 \pm 0.13$ \\
2nd research group $\left(\mathrm{TH}_{\mathrm{I}+\mathrm{Cu}}, n=30\right)$ & $22.25 \pm 4.73^{\#}$ & $3.98 \pm 0.19$ \\
\hline ** & $p_{1-2}<0.02$ &
\end{tabular}

**- $p<0.02{ }^{*}-p<0.01 ;{ }^{\#}-p<0.001$ to analogical indexes in intact animals; $p$ with Arabic numerals - reliable difference between the indexes of correspondent research groups (here and in the next tables).

2nd experimental group an increase in the content of end lipoperoxidation products more than in seven times $(p<0.001)$ was observed compared with similar data in rats of control group. Such changes were found against the background of a decrease in the content of DC by $43.9 \%(p<0.05)$.

It should be noted that the comparative analysis of the content of lipoperoxides in the blood serum of animals of the 1 st and 2nd experimental groups showed an increase in the content of TBA-AP by 3.2 times $\left(p_{1-2}<0.02\right)$ in rats with combined microelement deficiency. In the myocardial homogenate of rats with $\mathrm{TH}_{\mathrm{I}+\mathrm{Cu}}$, the activation of POL was mainly due to intermediate products, what is confirmed by an increase in their content by $48.2 \%(p<0.02)$ in animals of this group relative to the corresponding control values.

Correlation analysis found that the level of copper in red blood cells affects the content of DC in blood serum $(r=-0.70)$ and myocardium $(r=-0.82)$, which is confirmed by the presence of a strong correlation relationship.

Combined microelement deficiency also led to the activation of protein peroxide damage (POP) (Table 3). Thus, the manifestation of POP was observed mainly in the myocardial homogenate in rats of the 2 nd experimental group, what was indicated by the increase of the $\mathrm{E}_{430}$ fraction by 2.6 times $(p<0.001)$ compared to the baseline indicators. It should be noted that under conditions of $\mathrm{TH}_{\mathrm{I}+\mathrm{Cu}}$, the content of this OMP fraction increased by 2.2 times $\left(p_{1-2}<0.001\right)$ relative to similar values in animals with $\mathrm{TH}$ on the background of isolated iodine deficiency.

Correlation analysis revealed a strong inverse correlation between erythrocyte copper level and OMP content in myocardial homogenate $(r=-0.74)$.

The changes of peroxidation processes were followed by the redistribution of antioxidant enzymes activity (Table 4). In particular, rats with $\mathrm{TH}_{\mathrm{I}}$ showed a decrease in GR and STr activity by $60.0 \%(p<0.05)$ and $40.5 \%(p<0.05)$ respectively compared to the control. 
Table 3 The oxidative modification of proteins (AU.g protein) in the blood serum and myocardium homogenate of intact rats, animals with thyroid hypofunction on the background of iodine deficiency, combined iodine and copper deficiency (M $\pm \mathrm{m}$ ).

\begin{tabular}{lllll}
\hline Group of animal & $\mathrm{E}_{356}, \mathrm{~nm}$ & $\mathrm{E}_{370}, \mathrm{~nm}$ & $\mathrm{E}_{430}, \mathrm{~nm}$ & $\mathrm{E}_{530}, \mathrm{~nm}$ \\
\hline Control group $(n=30)$ & $3.09 \pm 0.82$ & $3.05 \pm 0.79$ & $1.21 \pm 0.47$ & $0.14 \pm 0.05$ \\
1st research group $\left(\mathrm{TH}_{\mathrm{I}}, n=30\right)$ & $2.06 \pm 0.42$ & $2.21 \pm 0.45$ & $0.77 \pm 0.20$ & $0.14 \pm 0.02$ \\
2nd research group $\left(\mathrm{TH}_{\mathrm{I}+\mathrm{Cu}}, n=30\right)$ & $2.06 \pm 0.30$ & $1.76 \pm 0.26$ & $0.61 \pm 0.11$ & $0.08 \pm 0.02$ \\
\hline \multicolumn{5}{c}{ Myocardium } \\
\hline Control group $(n=30)$ & $1.66 \pm 0.13$ & $1.74 \pm 0.13$ & $0.74 \pm 0.12$ & $0.06 \pm 0.08$ \\
1st research group $\left(\mathrm{TH}_{\mathrm{I}}, n=30\right)$ & $1.83 \pm 0.02$ & $1.89 \pm 0.02$ & $0.88 \pm 0.04$ & - \\
2nd research group $\left(\mathrm{TH}_{\mathrm{I}+\mathrm{Cu}}, n=30\right)$ & $1.95 \pm 0.08$ & $2.01 \pm 0.11$ & $1.95 \pm 0.11^{\# \#}$ & - \\
\hline
\end{tabular}

Table 4 Changes in the activity of antioxidant enzymes in the blood serum of intact rats, animals with thyroid hypofunction on the background of iodine deficiency, combined iodine and copper deficiency $(\mathbf{M} \pm \mathbf{m})$.

\begin{tabular}{|c|c|c|c|c|c|c|}
\hline Group of animals & $\begin{array}{l}\text { Catalase } \\
\mathrm{mg} \mathrm{H}_{2} \mathrm{O}_{2} \cdot \mathrm{mL}\end{array}$ & $\begin{array}{l}\text { Ceruloplasmin, } \\
\mathrm{cu}\end{array}$ & $\begin{array}{l}\text { Superoxide dismutase, } \\
\mathrm{cu} \cdot \mathrm{mg} \text { hemoglobine }\end{array}$ & $\begin{array}{l}\text { Glutathione } \\
\text { peroxidase } \\
\mu \mathrm{mol} \cdot \mathrm{mg} \text { protein }\end{array}$ & $\begin{array}{l}\text { Glutathione } \\
\text { reductase, } \\
\text { nmol·min'mg } \\
\text { protein }\end{array}$ & $\begin{array}{l}\text { Saturation of } \\
\text { transferrin with } \\
\text { iron, cu }\end{array}$ \\
\hline $\begin{array}{l}\text { Control group } \\
(n=30)\end{array}$ & $11.52 \pm 0.95$ & $53.61 \pm 14.30$ & $39.25 \pm 3.77$ & $0.19 \pm 0.04$ & $0.15 \pm 0.04$ & $0.37 \pm 0.03$ \\
\hline $\begin{array}{l}1 \text { st research group } \\
\left(\mathrm{TH}_{\mathrm{I}}, n=30\right)\end{array}$ & $13.67 \pm 0.61$ & $50.00 \pm 4.34$ & $31.20 \pm 1.41$ & $0.20 \pm 0.01$ & $0.06 \pm 0.01^{*}$ & $0.22 \pm 0.05^{*}$ \\
\hline $\begin{array}{l}2 \text { nd research group } \\
\left(\mathrm{TH}_{\mathrm{I}+\mathrm{Cu}}, n=30\right)\end{array}$ & $\begin{array}{l}6.10 \pm 0.89^{\#} \\
p_{1-2}<0.001\end{array}$ & $\begin{array}{l}35.42 \pm 4.20 \\
p_{1-2}<0.05\end{array}$ & $\begin{array}{l}26.67 \pm 1.32 * * \\
p_{1-2}<0.05\end{array}$ & $0.18 \pm 0.04$ & $\begin{array}{l}0.42 \pm 0.15 \\
p_{1-2}<0.05\end{array}$ & $0.16 \pm 0.02^{\# \#}$ \\
\hline
\end{tabular}

Table 5 Changes of morphometric indexes of myocardium of intact rats, animals with thyroid hypofunction on the background of iodine deficiency, combined iodine and copper deficiency $(\mathbf{M} \pm \mathbf{m})$.

\begin{tabular}{llllll}
\hline Group of animals & $\begin{array}{l}\text { Fraction of } \\
\text { interstitium, } \%\end{array}$ & $\begin{array}{l}\text { Fraction of } \\
\text { parenchyma, \% }\end{array}$ & $\begin{array}{l}\text { Parenchymal-inters Cardiomyocyte } \\
\text { titial index }\end{array}$ & $\begin{array}{l}\text { Cardiomyocyte } \\
\text { nucleus area, } \mu \mathrm{m}^{2}\end{array}$ & nucleus perimeter, $\mu \mathrm{m}$ \\
\hline $\begin{array}{l}\text { Control group } \\
(n=30)\end{array}$ & $0.63 \pm 0.03$ & $99.37 \pm 3.31$ & $158.49 \pm 6.34$ & $50.76 \pm 2.34$ & $32.72 \pm 2.36$ \\
$\begin{array}{l}1 \text { st research group } \\
(\mathrm{TH}, n=30)\end{array}$ & $5.98 \pm 0.24^{\# \#}$ & $89.66 \pm 2.99$ & $15.00 \pm 0.75^{\# \#}$ & $29.65 \pm 0.86^{\# \#}$ & $24.81 \pm 1.33^{* *}$ \\
$\begin{array}{l}\text { 2nd research group } \\
\left(\mathrm{TH}_{\mathrm{I}+\mathrm{Cu}}, n=30\right)\end{array}$ & $\begin{array}{l}13.55 \pm 0.52^{\# \#} \\
p_{1-2}<0.001\end{array}$ & $86.45 \pm 2.76^{* *}$ & $\begin{array}{l}6.38 \pm 0.32^{\# \#} \\
p_{1-2}<0.001\end{array}$ & $32.94 \pm 1.33^{\# \#}$ & $26.44 \pm 1.57$ \\
\hline
\end{tabular}

Common, but more significant, were changes in the system of antiradical defense under conditions of combined microelementosis. Thus, in the blood serum of animals of the 2nd experimental group a decrease in K activity—by $47.0 \%(p<0.01)$, SOD—by $32.0 \%(p$ $<0.02)$ and $\mathrm{STr}$ - by $56.8 \%(p<0,001)$ was observed in comparison to similar values of intact animals. During the comparative analysis of the antioxidant system of rats in both research groups, the opposite directed changes in the activity of examined enzymes were established. In particular, under the conditions of $\mathrm{TH}_{\mathrm{I}+\mathrm{Cu}}$ the activity of $\mathrm{K}, \mathrm{CP}$ and SOD of the blood serum decreased by $14.5-55.4 \%\left(p_{1-2}<0.05\right)$ against the background of increased activity of GR by seven times $\left(p_{1-2}<0.05\right)$ in relation to the relevant indicators in animals with $\mathrm{TH}$ in case of isolated iodine deficiency.

Metabolic changes of the myocardium of rats with TH were consistent with the structural, which was manifested more pronounced under conditions of combined trace elements deficiency (Table 5). Thus, in case of $\mathrm{TH}_{\mathrm{I}+\mathrm{Cu}}$ cytoplasm of cardiomyocytes was unevenly colored, the borders of the sarcolemma were blurred, the striated structure was not clearly traced, the nuclei were recruited with enlightened karyoplasm, their area was by $35.1 \%(p<0.001)$ smaller than similarly index in intact animals. In the myocardium, the areas of the syncytium bundle were visualized with 

Myocardium of Rats in Conditions of Thyroid Hypofunction

bunches of swollen connective tissue. Due to it, the part of interstitium exceeded the corresponding index in rats of the 1 st experimental group 2.3 times $\left(p_{1-2}<\right.$ 0.001 ), which was significantly ( 21.5 times, $p<0.001$ ) higher than the initial data. The part of parenchyma, on the contrary, decreased by $13.0 \%(p<0.02)$ relative to control data. Hence, the parenchymal-interstitial index decreased by $57.5 \%\left(p_{1-2}<0.001\right)$ compared to the same indicator in animals of the 1st experimental group, which was by $96.0 \%(p<0.001)$ less than the control data. Structural changes were found also in the walls of coronary vessels. In particular, the intima of arteries was swollen, the sarcoplasm of smooth myocytes of the middle membrane was enlightened, and in the adventitia edema was found. In some intramural arterioles, the lumen was not traced at all.

\section{Discussion}

In animals with $\mathrm{TH}_{\mathrm{I}+\mathrm{Cu}}$, the redistribution of copper content in the examined tissues was found-a significant increase in red blood cells on the background of a decrease in myocardium. Considering the essential importance of the trace element for the physiological course of many metabolic processes in the heart muscle, such changes may be a severe risk factor for the development of cardiac pathology. The results of the study confirm the activation of oxygen-dependent processes in the myocardium of experimental animals, primarily due to POP, which is especially manifested in the context of combined iodine and copper deficiency.

It is established that at the initial stage of changes in cellular homeostasis exactly the processes of modification of protein nature biomolecules are the most significant. Therefore, it can be assumed that the accumulation of OMP in the myocardium serves as a marker of early metabolic disorders in the myocytes [11]. Along with the activation of POP in the myocardial homogenate, the intensity of lipoperoxidation also increased, which may potentiate dysmetabolic changes in the heart [12].

\section{Conclusions}

$\mathrm{TH}$ on the background of copper deficiency increases the probability of cardiovascular pathology due to disorders of prooxidant-antioxidant balance, accompanied not only by functional violations of cardiac activity, but also by structural changes in the myocardium. Considering the impact of hypocupremia, not only on the course of metabolic processes in the heart, but also on the synthesis of iodine hormones of thyroid gland, it is advisable to determine the microelement panel, and if necessary to appoint copper-containing mineral complexes for the treatment and prevention of cardiac diseases against thyroid pathology.

\section{References}

[1] Zhuravlyova, L. V., and Filonenko, M. V. 2016. "The Impact of Selenium Homeostasis on Development and Prognosis of Cardiovascular Diseases." Medicine of Ukraine 7-8 (203-204): 28-31.

[2] Marushko, Y. V., and Grachova, M. G. 2013. "The Role of Deficiency of Copper Content in the Organism for the Clinical Practice." Pediatrician 2 (23): 11-6.

[3] Yuzvenko, T. Y. 2014. "Influence of Hypothyroidism on Separate Links of Metabolism, Structure and Function of the Heart in Insulin Resistance." International Endocrinological Journal 4 (60): 31-5.

[4] Zubkova, S. T., and Mikhaylenko, O. Y. 2016. "Cardiac and Vascular Remodeling in Patients with Hypothyroidism, Associated with Hypertension." Endocrynology 21 (2): 131-6.

[5] Voronych-Semchenko, N. M. 2014. "Changes of Processes of Free Radical Oxidation of Lipids and Proteins, Antioxidant Defense in Rats with Hypofunction of Thyroid Gland on the Background of Iodine and Copper Deficit." Physiological Journal 60(4): 30-9.

[6] Charnosh, S. M. 2014. "Cholinergic Mechanisms of Chronotropic Function of the Heart at Hypothyroidism." Clinical and Experimental Pathology 1 (47): 149-52.

[7] Yamamoto, M., Aklyama, C., and Aikawa, H. 1990. "D-penicillamine-Induced Copper Deficiency in Suckling Mice: Neurogical Abnormalities and Brain Mitochondrial Enzyme Activities." Developmental Brain Research 55 (1): 51-5.

[8] Pankiv, V. I. 2016. "State of Mineral Density of Bone Tissue of Women in Postmenopausal Period with Primary Hypothyroidism." Clin \& Exper Pathol 15 (1): 104-10. 
Influence of Copper Deficit on Structural and Metabolic Features of Myocardium of Rats in Conditions of Thyroid Hypofunction

[9] Ivanusa, I. V. 2015. "Features of Free Radical Oxidation and Antioxidant System Parameters of Animals at Acute Toxic and Subchronic Poisoning by Acetaminophen with Prolonged Usage of Estrogen and Progestin at the Correction by Thiotriazoline and Hepadif." Pharmaceutical Review 2: 101-7.

[10] Guranych, S. Sokyrko, I., Guranych, T., and Stetsevyat, V. 2017. "Lipid and Protein Peroxidation in Rats with Iodine Deficiency, Insulin Resistance and in Terms of Their Combination." TEKA Archives of the Commission of
Medical Sciences 5 (1): 101-6.

[11] Pochynok, T. V., Veselova, T. V., and Gorobets, N. I. 2016. "Protein Peroxidation and Lipid Peroxidation in Children with Undifferentiated Dysplasia of Connective Tissue." Modern Pediatry 2 (74): 36-41.

[12] Lototska, O. V. 2013. "Lipid Peroxidation and Antioxidant Protection in the Body of Experimental Animals under Subtoxic Copper Doses on Background Use Drinking Water with Different Content of Potassium Stearate." Actual Problems of Transport Medicine 3 (33): 139-45. 